\title{
IFNs and STATs in innate immunity to microorganisms
}

\author{
Thomas Decker, ${ }^{1}$ Silvia Stockinger, ${ }^{1}$ Marina Karaghiosoff,, 2 Mathias Müller, ${ }^{2}$ \\ and Pavel Kovarik ${ }^{1}$ \\ ${ }^{1}$ Vienna Biocenter, Institute of Microbiology and Genetics, Vienna, Austria \\ ${ }^{2}$ Institute of Animal Breeding and Genetics, Veterinary University of Vienna, Vienna, Austria \\ Address correspondence to: Thomas Decker, Vienna Biocenter, Institute of Microbiology and Genetics, \\ Dr. Bohr-Gasse 9, A1030 Vienna, Austria. \\ Phone: 43-1-4277-54605; Fax: 43-1-4277 9546; E-mail: decker@gem.univie.ac.at.
}

J. Clin. Invest. 109:1271-1277 (2002). doi:10.1172/JCI200215770.

Innate immune responses derive from the ability of cells to rapidly combat invading microorganisms without the requirement for an antigen-specific adaptation. These mechanisms have evolved to recognize common microbe-associated molecular patterns and to interfere with conserved replication and survival strategies that support the propagation of microbial invaders. Here, we consider the contributions of one cytokine family, the IFNs, to these innate defense mechanisms. IFNs were first recognized for their ability to impede viral replication, a function that is indeed critical for host survival in response to viral infection. In addition, IFN signaling is now known to play key roles in defending the host from bacteria and other pathogens and to help integrate early, innate responses with later events mediated by the adaptive immune system.

The two recognized types of IFN exhibit distinct immunological properties (1). In humans and mice, type I IFNs include a number of IFN- $\alpha$ subtypes and a single species of IFN- $\beta$. (The immunological impact of another type I IFN, IFN- $\omega$, is poorly understood and will not be considered here). While type I IFNs can be produced by all cells under appropriate conditions, a subpopulation of immature dendritic cells (DCs) that will be described in more detail below stands out for the extent of its contribution to overall IFN production during infections. IFN- $\gamma$ is a type II IFN and serves not only to induce antiviral function, but also to activate macrophages, which strengthens innate responses to unicellular microorganisms (2). Unlike the type I IFNs, IFN- $\gamma$ is produced by a limited number of cell types: activated NK cells, activated Th1 cells, and, in the presence of IL-12 and IL-18, activated DCs and macrophages. Expression of IFN- $\gamma$ by Th 1 cells provides an important link by which the adaptive immune response reinforces macrophage-based innate immunity.

\section{JAK-STAT signaling in IFN responses}

A common property of both IFN types is to induce immediate transcriptional responses through a JAKSTAT signal transduction pathway (3). All type I IFNs bind to a class II cytokine receptor composed of IFN- $\alpha$ receptor 1 (IFNAR1) and IFNAR2 chains, which are associated with the Janus kinases (JAKs) TYK2 and JAK1, respectively. Ligand-bound, tyrosine-phosphorylated receptor complexes bind the $\mathrm{SH} 2$ domains of signal transducers and activators of transcription (STATs) 1 and 2, causing phosphorylation of the proteins on tyrosines 701 and 692, respectively. Interaction of STATs through reciprocal SH2 domain-phosphotyrosine binding results in formation of two distinct transcription factor complexes. ISGF3, a heteromeric complex consisting of STAT1 and STAT2 in association with a third protein, $\mathrm{p} 48$ or IRF9, associates specifically with and transactivates genes with interferon-stimulated response elements (ISRE) in their promoter or enhancer regions. A simpler complex, consisting solely of the STAT1 homodimer, is also active as a transcription factor and binds to different DNA sequences, termed IFN- $\gamma$-activated site (GAS) elements (Figure 1).

The receptor for IFN- $\gamma$ is structurally related to that for type I IFN. It consists of IFN- $\gamma$ receptor 1 (IFNGR1) and IFNGR2 chains in association with JAK1 and JAK2 kinases. Once tyrosine-phosphorylated in the presence of ligand, it binds STAT1 and causes phosphorylation of Y701. STAT1 homodimers are formed, move to the nucleus, and regulate transcription of promoters containing GAS sequences (Figure 1; ref. 4). Recent evidence indicates that nuclear responses can be stimulated by IFN- $\gamma$ in the absence of STAT1 (5), but the transcription factors mediating the STAT1-independent response remain to be identified. In addition, some genes are induced by IFN- $\gamma$ only in the absence of STAT1, suggesting that this protein can also mediate transcriptional repression.

\section{Innate immunity to viruses}

Cells in culture respond to viruses by deploying a complex network of signaling molecules that initiate and then amplify the production of type I IFNs. At an early 


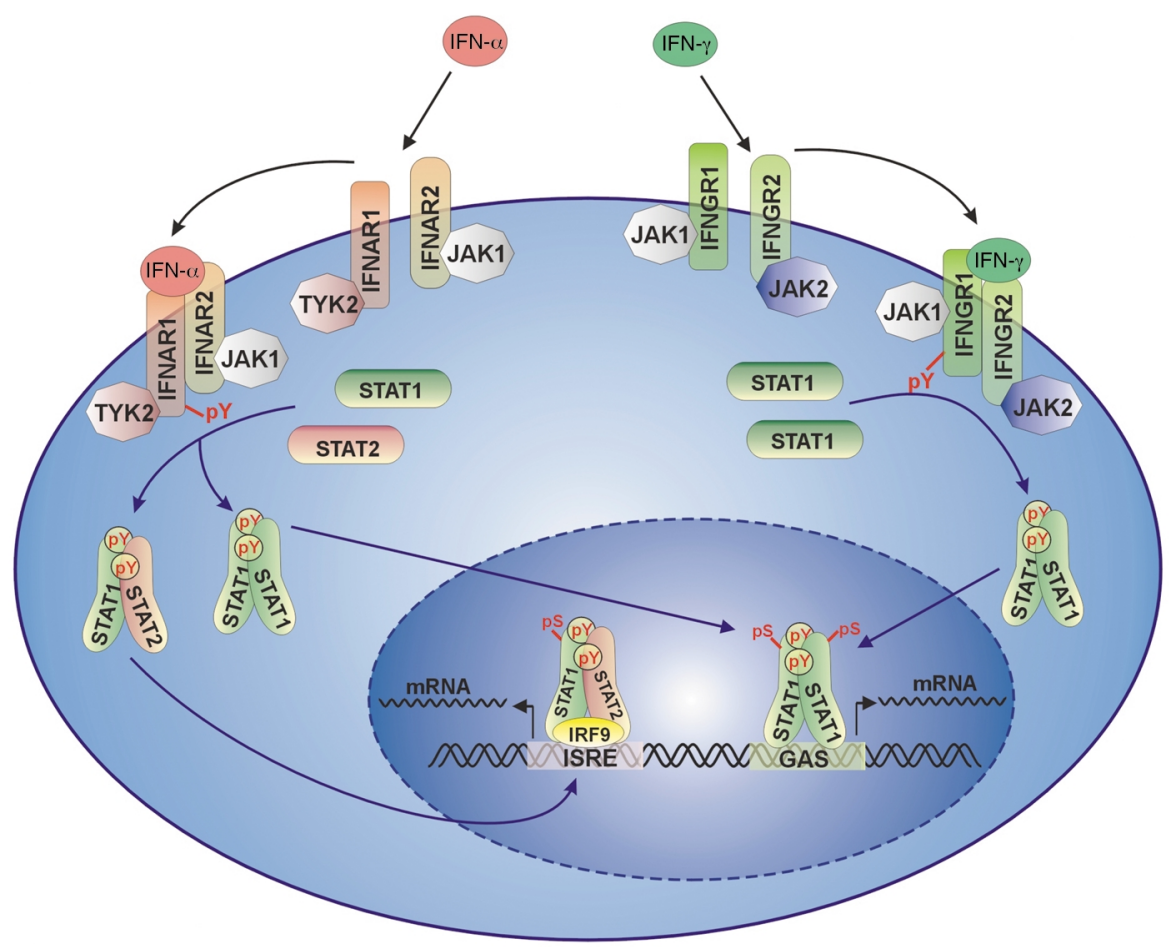

\section{Figure 1}

JAK-STAT signal transduction in response to type I and type II IFNs. Upon binding of ligand, IFN receptor-associated Janus kinases (JAKs) are activated and phosphorylate receptor chains on tyrosine. Cytoplasmic signal transducers and activators of transcription (STATs) bind to the phosphorylated receptors with their SH2 domains. JAKs associated with the type I IFN receptor (IFNAR) then phosphorylate STAT1 and STAT2 on tyrosine, causing the formation of predominantly STAT1-STAT2 heterodimers, and of STAT1 homodimers. IFN- $\gamma$ receptor-associated (IFNGR-associated) JAKs phosphorylate STAT1, leading to the formation of STAT1 homodimers. STAT dimers translocate to the cell nucleus. Thereafter, STAT1-STAT2 heterodimers associate with a third protein, IRF9, and bind one class of type I IFN response elements, the ISRE, whereas STAT1 homodimers activate gene expression by binding to another class of IFN response elements, the GAS.

step in this pathway, the transcription factor IFN regulatory factor 3 (IRF3) becomes phosphorylated on serine residues by a still-unidentified kinase. Activated IRF 3 then stimulates transcription of IFN- $\alpha 4$ and IFN- $\beta$, and these secreted "early" IFNs activate ISGF3 and its target gene Irf7. IRF7 closes a positive feedback loop of IFN production by initiating a second, larger wave of IFN gene expression, consisting of non- $\alpha 4$ IFN- $\alpha$ subtypes. Studies in virus-infected mice confirm the importance of the IRF7-dependent positive feedback loop but show that its relative contribution to overall IFN production varies. Some viruses cause secretion of the non- $\alpha 4$ IFN- $\alpha$ subtypes already early during infection. Constitutive expression of IRF7, or the employment of another IRF family member, e.g., IRF5, in the producing cell have been proposed as potential molecular causes for immediate production of all IFN- $\alpha$ subtypes (reviewed in ref. 6). In support of the positive feedback model, deletion of genes encoding the ISGF3 subunits blocks IFN production and thereby reduces antiviral responses $(7,8)$. Loss of IFN- $\beta$, likewise, reduces IFN- $\alpha$ production by virusinfected fibroblasts and increases sensitivity of mice to Vaccinia virus (9).

Although a number of type I IFN-stimulated genes (ISGs) show a clear link to the antiviral state (Table 1), mechanisms of action for most of these are poorly understood. Many have been cloned by cDNA subtraction or related methods and have not been shown to contribute to the antiviral state. Studies in genetargeted mice clearly support a decisive role of the ISGF3 complex and its target genes in type I IFN-dependent innate immunity to virus. The individual knockouts of all three ISGF3 subunits cause severe loss of resistance to viruses, apparently of a similar magnitude to that resulting from disruption of Ifnar1 (10-13). Since STAT1 is a component of ISGF 3 and contributes to both IFN- $\alpha / \beta$ and IFN- $\gamma$ responses, it has been difficult to assess the role of STAT1 dimer target genes specifically in type I IFN responses. Experiments in genetically modified human cell lines suggest it may be of minor importance, but IFN- $\gamma$-treated cells are thought to achieve their potent antiviral state primarily through the action of the STAT1 dimer, rather than through activation of ISGF3 target genes.

The importance of type I IFN in innate antiviral responses is clear from studies in mice with targeted disruption of either Ifnar1 or Stat2 $(13,14)$. Such mice fail to clear a variety of viruses, such as vesicular stomatitis virus (VSV), Semliki Forest virus (SFV), Vaccinia virus (VV), and lymphocytic choriomeningitis virus (LCMV) and are prone to die from the corresponding viral infections. The loss of virus-specific cytotoxic T lymphocyte 
(CTL) responses seen in Ifnar1 $1^{-/-}$mice is thought to result from exhaustion of cytotoxic $\mathrm{T}$ cells due to overwhelming viral burden (14). Since IFN-nonresponsive mice do not display a general impediment in mounting adaptive immune responses, the main defect in antiviral immunity is likely to result from the innate component, the establishment of an antiviral state. Besides producing an antiviral state, the IFNs (particularly the type I IFNs) can affect the rate at which infected cells undergo apoptosis (15). The contribution of this apoptotic response to viral clearance not known.

A fairly complex picture of IFN function has emerged from studies with influenza virus. Mouse lines with a wild-type allele of the type I IFN-inducible $M x$ gene

Table 1

IFN-induced genes with known function in innate immunity

\begin{tabular}{|c|c|c|c|}
\hline Gene & Description & Specific function & Inducing IFN \\
\hline $2-5 \mathrm{~A}$ synthetase & $2^{\prime}-5^{\prime}$-oligoadenylate synthetase & $\begin{array}{l}\text { Products of } 2-5 A \text { synthetase activate latent riboendonuclease } \\
\text { RNaseL that degrades single-stranded RNA molecules of viral } \\
\text { and cellular origin }\end{array}$ & Types I and II \\
\hline RNaseL & $\begin{array}{l}\text { Riboendonuclease activated by } 2^{\prime}, 5^{\prime} \text {-linked } \\
\text { oligonucleotides }\end{array}$ & $\begin{array}{l}\text { Degrades both viral and cellular RNA upon viral infection, resulting } \\
\text { in apoptosis and virus inhibition }\end{array}$ & Type I \\
\hline PKR & $\begin{array}{l}\text { Double-stranded RNA-activated protein } \\
\text { serine/threonine kinase }\end{array}$ & $\begin{array}{l}\text { Important for the induction of antiviral state; inhibits protein } \\
\text { synthesis, plays a role in regulating (IFN) gene expression }\end{array}$ & Types I and II \\
\hline Mx1 and 2 & GTP-binding proteins with GTPase activity & $\begin{array}{l}\text { Possess strong antiviral potential; mechanism of action } \\
\text { not well understood }\end{array}$ & Type I \\
\hline GBP1 and 2 & Guanylate-binding proteins & Exhibit antiviral properties; mechanism of action not understood & Type II \\
\hline PML, SP100 & $\begin{array}{l}\text { Localized to promyelocytic oncogenic domains } \\
\text { (PODs) in the nucleus }\end{array}$ & $\begin{array}{l}\text { Required for IFN-induced transcriptional repression of retroviral } \\
\text { genes; inhibit replication of DNA tumor viruses }\end{array}$ & Type 1 \\
\hline p56 & $56-\mathrm{kDa}$ translation inhibitor & $\begin{array}{l}\text { Virus, double-stranded RNA and IFN-induced inhibitor of the } \\
\text { eukaryotic translation initiation factor } 3\end{array}$ & Type I \\
\hline $\begin{array}{l}\beta_{2} \mathrm{~m} \\
\text { TAP1 }\end{array}$ & $\beta_{2}$-microglobulin & Antigen presentation & Type I and II \\
\hline TAP2 & $\begin{array}{l}\text { Transporters associated with antigen } \\
\text { presentation }\end{array}$ & $\begin{array}{l}\text { Essential for transport of peptides from cytosol to the endoplasmic } \\
\text { reticulum and peptide loading of } \mathrm{MHC} \text { class I molecules }\end{array}$ & Type II \\
\hline LMP2 & $\begin{array}{l}\text { Proteasomal component, low-molecular } \\
\text { weight protein }\end{array}$ & Important for production of peptides for MHC class I loading & Type II \\
\hline GILT & IFN- $\gamma$-inducible lysosomal thiol reductase & $\begin{array}{l}\text { Facilitates antigen processing and presentation by reducing disulfide } \\
\text { bonds of antigens in late endosomes }\end{array}$ & Type II \\
\hline CIITA & $\begin{array}{l}\text { Transcription factor involved in expression } \\
\text { of MHC class I and II molecules }\end{array}$ & Antigen presentation & $\begin{array}{l}\text { Predominantly } \\
\text { type II }\end{array}$ \\
\hline gp91-phox & $\begin{array}{l}\text { Heavy-chain subunit of the cytochrome b558 } \\
\text { that is a component of } \mathrm{NADPH} \text { oxidase }\end{array}$ & Involved in respiratory burst & Type II \\
\hline iNOS (NOS2) & Inducible nitric oxide synthase & $\begin{array}{l}\text { Protective role against protozoan, bacterial, and some viral } \\
\text { infections. iNOS negatively influences the clearance of infection } \\
\text { with Mycobacterium avium }\end{array}$ & Types I and II \\
\hline NRAMP1 & $\begin{array}{l}\text { Natural resistance-associated macrophage } \\
\text { protein }\end{array}$ & $\begin{array}{l}\text { Confers resistance to infection with intracellular pathogens, such as } \\
\text { Mycobacterium, Salmonella, and Leishmania; involved in the delivery of } \\
\text { intracellular bactericidal agents to endosomes }\end{array}$ & Type II \\
\hline Rab5a & GTPase & $\begin{array}{l}\text { Facilitates translocation of Rac2 to bacteria-containing } \\
\text { phagosomes (shown for Listeria monocytogenes), which governs the } \\
\text { NADPH oxidase activity and, hence, oxidative burst }\end{array}$ & Type II \\
\hline $\begin{array}{l}\text { IGTP } \\
\text { LRG-47 } \\
\text { GTPI } \\
\text { IRG-47 } \\
\text { TGTP/Mg2 }\end{array}$ & & & \\
\hline IIGP & $\begin{array}{l}\text { Group of } 47-\text { to } 48-k D a \text { GTPases likely } \\
\text { to be involved in protein trafficking }\end{array}$ & $\begin{array}{l}\text { Protection against protozoan and bacterial pathogens. The } \\
\text { requirement for each member depends on the type of pathogen }\end{array}$ & Mostly type II \\
\hline IDO & Indoleamine 2,3-dioxygenase & $\begin{array}{l}\text { Catalyzes decyclization of L-tryptophan thereby limiting } \\
\text { the availability of this amino acid to intracellular microorganisms }\end{array}$ & Type II \\
\hline $\begin{array}{l}\text { RANTES } \\
\text { MIP- } 1 \alpha \text { and MIP } \\
\text { MCP- } 1\end{array}$ & & & \\
\hline IP-10 & Chemokines & $\begin{array}{l}\text { 8- to } 10-\mathrm{kDa} \text { secreted proteins capable of regulating migration, } \\
\text { activation, and maturation of leukocytes; important for orchestrating } \\
\text { interactions between innate and adaptive immune systems }\end{array}$ & Mostly type II \\
\hline
\end{tabular}


show increased resistance compared with those with a mutated $M x$, corroborating cell culture studies indicating that $\mathrm{Mx}$ can efficiently interfere with influenza virus replication (16). In Mx-deficient mice (including most inbred mouse lines), type I IFN and STAT1 determine the tissue tropism of influenza infection $(17,18)$. In infected lungs, where the antiviral state makes only a minor contribution to viral clearance, the major effect of IFN is to regulate the inflammatory environment. When a hemorrhagic form of the influenza virus progresses beyond the respiratory system in an Mx-deficient animal, the type I IFN- and STAT1-dependent antiviral state of infected cells appears to be a major determinant for its clearance.

The importance of IFN- $\gamma$ in innate antiviral immunity depends greatly on the type of infecting virus. While IFN- $\gamma$-deficient mice and IFNGR1-deficient mice show an unimpaired ability to cope with VSV or SFV infections, their susceptibility to VV or to LCMV is strongly increased $(14,19,20)$. Indeed, mice in which both Ifnar 1 and Ifngr 1 are disrupted display an additive susceptibility to VV and LCMV, compared with the individual knockouts (21). Taken together, the studies suggest that in animals, the two IFN types are complementary and to some extent nonredundant with respect to innate resistance to different viral pathogens. Whether this reflects different conditions of synthesis, a qualitative difference of the respective antiviral states, or distinct immunoregulatory properties still needs to be clarified.

\section{Innate immunity to bacteria and protozoa}

Many cell types, particularly macrophages and DCs, produce type I IFN following exposure to bacteria and protozoa (22). In most cases, the molecular mechanism by which type I IFN synthesis is stimulated is unknown. However, IRF3 has been shown to be activated by LPS $(23,24)$ or by infection of macrophages with the intracellular pathogen Listeria monocytogenes (S. Stockinger and T. Decker unpublished observations), suggesting that, as in viral infections, this transcription factor may be an important mediator of bacteriainduced IFN production.

The contribution of type I IFNs to innate immunity against bacteria or protozoa appears to vary with the particular microorganism. The mortality of IFNAR1- or STAT2-deficient mice after infection with $L$. monocytogenes is similar to that of wild-type mice $(13,21)$, but the bacterial loads found in livers and spleens are significantly lower in STAT2-deficient than in wild-type mice (C. Schindler, personal communication). Studies from our laboratories show that type I IFNs sensitize infected macrophages to $L$. monocytogenes-induced cell death in a STAT1-dependent manner (S. Stockinger et al., unpublished observations). Whether this is the underlying cause of the adverse effect of type I IFN in vivo remains to be shown. Likewise, there are few experimental data to indicate whether type I IFNs generally delay the clearance of intracellular bacteria. In support of this notion, a study of mice infected with Mycobacterium tuberculosis reported that bacterial virulence correlates directly with the ability to produce type I IFNs, and that the administration of recombinant IFN- $\alpha$ exacerbates lung disease (25). However, an independent examination of $M$. tuberculosis infection found a slightly enhanced replication of the bacteria in the lungs of IFNAR1-deficient mice compared with wildtype controls (26). Therefore the impact of type I IFN may vary with yet undefined parameters of the hostpathogen interplay.

Like L. monocytogenes, the protozoan parasite Leishmania major multiplies inside macrophages. Howev$\mathrm{er}$, in this case, mice benefit from the synthesis of and response to type I IFNs (27), which synergize with the parasite in stimulating the expression of inducible nitric oxide synthase (NOS2 or iNOS); NO production appears to limit the spread of the pathogen in the infected host. Exposure to LPS or viruses, as well as to L. major, induces expression of NOS2, particularly in the presence of type I IFN. The importance of this synergistic response is clear in the case of LPS, where the bacterial product stimulates macrophages to produce IFN and both together then stimulate NOS2 expression. This model of IFN- $\beta$ 's role as a secondary mediator of responses to bacterial stimuli of toll-like receptor 4 (TLR4) appears to apply more generally to genes linked to JAK-STAT signaling (28) and has been validated by work in Tyk2-deficient mice (29). Due to their lower production of, and lower responsiveness to, type I IFNs, macrophages from these mice fail to produce NO following LPS treatment. Taken together, these findings suggest that type I IFNs and their stimulation of JAK-STAT signaling may be advantageous where NO is crucial in clearing or limiting an infection.

IFN- $\gamma$ appears to act by at least two distinct mechanisms to augment innate cellular immunity. The main target of IFN- $\gamma$ activity is the macrophage, and a plethora of investigations document the increased ability of IFN- $\gamma$-activated macrophage cultures to kill ingested bacterial or protozoan pathogens (2). The NADPH oxidase subunits, NOS2, lysosomal enzymes, and tryptophan-metabolizing enzymes involved in the killing of ingested microorganisms by, respectively, reactive oxygen species, NO radicals, breakdown, and tryptophan depletion - are among the gene products induced by IFN- $\gamma$ (Table 1$)$. Some of these factors have been shown to be regulated by STAT1, explaining the increased susceptibility of STAT1-deficient mice to bacterial pathogens. In addition to arming macrophages for enhanced killing of microbes, a second important function of IFN- $\gamma$ is to enhance the synthesis of cytokines that contribute to antimicrobial immunity in vivo. The IL-12 p40 subunit represents one well-documented example, but a similar situation may apply to TNF- $\alpha$, IL-1, and possibly other cytokines.

Converging evidence from a number of different experimental approaches demonstrates the importance of IFN- $\gamma$ in host defense, particularly against pathogens spending at least part of their life cycle 
inside cells, such as species of the genera Listeria, Mycobacterium, Salmonella, Chlamydia, and Leishmania (11, 19-21, 30-33). Treatment with recombinant IFN- $\gamma$ or, conversely, abrogation of IFN- $\gamma$ responsiveness (either genetically or by treating with neutralizing antibodies) consistently reveals the cytokine to be a major determinant of pathogen persistence or clearance and of host survival. Remarkably, the impact of IFN- $\gamma$ can vary considerably among species of a given bacterial genus, as in the case of Mycobacterium (34), or even among different attenuated variants of Salmonella typhimurium carrying mutations in different virulence genes (35). Hence, there must be a close relationship between particular virulence strategies and the IFN- $\gamma$-dependent defense mechanisms.

Infection studies in mice make it hard to distinguish the effects of IFN- $\gamma$ on innate immunity, like the activation of macrophages, from its effects on adaptive immunity, like the generation of Th 1 cells and CTLs. However, the importance of the former responses, at least during the initial exposure to a pathogen, is seen in studies like that of Harty and Bevan (36), who found that naive animals resist virulent $L$. monocytogenes mainly through IFN- $\gamma$-dependent innate immunity, with NK cells being the main source of IFN- $\gamma$ (37). By contrast, immune animals combat the bacterium in a CTL-dependent, but largely IFN- $\gamma$-independent, fashion. The crucial roles of IFN- $\gamma$ and STAT1 in defense against intracellular pathogens have also been demonstrated in humans with mutations in STAT1 or the IFN- $\gamma$ receptor chain genes $(38,39)$. In all cases, these mutations result in an increased susceptibility to infection with Mycobacterium. The STAT1 mutation (L706S) reported by Dupuis and colleagues (39) is particularly interesting because it behaves as a dominant with regard to the formation of a STAT1 dimer in response to IFN- $\gamma$, but as a recessive with regard to the formation of ISGF3 upon IFN- $\alpha$ treatment. As a result, heterozygous individuals display an increased risk of contracting mycobacterial and other bacterial infections, but an apparently normal innate response against viral pathogens. This finding is consistent with previous suggestions that ISGF3 target genes are sufficient to build up an antiviral state against most viruses, but that STAT1 dimer target genes are required for innate immunity against intracellular bacteria. Bacteria and their products can directly influence STAT1's activity as a transcription factor. In addition to phosphorylation on Y701, STAT1 must be phosphorylated on S727, in its carboxy-terminal transactivation domain, for full activity (40). Whereas bacteria do not directly induce the former modification, they can rapidly stimulate STAT1 S727 phosphorylation via p38MAPK $^{\text {M }}$ (4), leaving STAT1 primed for increased transcription factor activity following IFNstimulated tyrosine phosphorylation. Complicating this model of the effects of microbial infection is the finding that a prolonged encounter of macrophages with bacteria leads to the synthesis of suppressors of cytokine signaling (SOCS), proteins that can block the action of specific STATs $(41,42)$. Therefore, the duration of the bacterial stimulus on macrophages is of critical importance for its effect on transcriptional responses to IFN. The complexity of the situation makes it hard to assess the importance of the interplay of bacterial and IFN stimuli on JAK-STAT signaling in an infected host.

\section{Regulation of dendritic cell and NK cell function}

An important property of the innate immune system is that it translates its encounter with microorganisms into an appropriate stimulation of the adaptive immune system. For several reasons, DCs represent a major link between the innate and adaptive immune responses (43). DCs are the most potent antigen-presenting cells and the dominant cell type in the activation of naive T cells. Different subsets of DCs are thought to determine which type of immunity dominates the response to a given antigen (44). In humans, DC1 (myeloid) and DC2 (plasmacytoid) subsets have been defined based on their ability to produce, respectively, high or low amounts of IL-12 and thus to promote the generation of Th1 or Th2 cells. However, the simple beauty of this model has not held up on further study: DC1 and DC2 cells, maturing from their pre-DC1 and pre-DC2 progenitors under various conditions, show a high degree of plasticity with respect to their ability to stimulate Th1 or Th2 differentiation (45).

Among human leukocytes, pre-DC2 cells represent the major type I IFN-producing cells $(46,47)$. Production of IFN can be stimulated by microbes or their products - viral surface components; double-stranded RNA $(48,49)$, a ligand of TLR3; and nonmethylated CpG oligonucleotides (50), a ligand for TLR9. The vast quantities of type I IFNs produced following exposure to any of these inducers influence the biology of DCs in several respects. First, they promote preDC2 differentiation to DC2 by serving as a survival factor (51). In addition, they alter the character of the downstream DC and T cell response. Unlike DC 2 cells maturing in the presence of IL-3, which cause Th2 differentiation, virus-induced DC2 cells induce the generation of a Th subset producing large amounts of IFN- $\gamma$ as well as IL-10 (51). In this situation, DC2derived IFN- $\alpha$ most likely stimulates the synthesis of IFN- $\gamma$ by T cells, bypassing the usual requirement for IL-12. Because IFN- $\alpha$ suppresses the ability of CD14 monocytes to mature to DCs (52) and promotes the apoptosis of monocyte-derived DCs in response to bacterial stimuli (53), it appears that the maturationpromoting effect of type I IFN is restricted to plasmacytoid pre-DCs. As in humans, an immature DC $\left(\mathrm{CD} 11 \mathrm{c}^{+}, \mathrm{Gr}-1^{+}, \mathrm{B} 220^{+}\right)$synthesizing large quantities of IFN has been identified in mice and shown to belong with a plasmacytoid, CD8- DC subpopulation $(54,55) . \mathrm{CD}^{+}$and CD8- ${ }^{-}$Des in mice are usually taken to correspond to the human DC1 and DC2 subpopulations, respectively. Finally, IFN- $\alpha$ has been implicated in DC cross-inhibition, whereby DC2s suppress IL-12 production by DC1s (56). 
Work with IFNAR-deficient mice confirms the importance of DC-derived type I IFNs and DC responses to these cytokines for priming a clonal immune response. In wild-type mice, IFN- $\alpha$ efficiently substitutes for CFA in the generation of an efficient humoral immune response. Consistent with this, CFA itself fails to show normal adjuvant activity in the absence of IFNAR expression, and adoptively transferred wild-type DCs can rescue the adjuvant activity of type I IFN in Ifnar $/-$ mice (57). Together, the data suggest a model for adjuvant responses in which the bacterial components (in CFA, for example) stimulate TLRs, which promote type I IFN production. This in turn stimulates DCs to generate and activate Th cells. The finding that human DC subsets differ in their expression of individual TLRs (50) suggests that type I IFN production and the subsequent generation of adaptive immune responses vary depending on which microbe stimulates one or another DC subset.

NK cells play an important role as producers of IFN- $\gamma$. NK cell-derived IFN- $\gamma$ activates macrophages and serves later in the course of an immune response as a regulator of Th differentiation. Human and murine NK cells behave differently when stimulated by type I IFNs. As with Th cells, human but not murine NK cells produce IFN- $\gamma$ in response to these cytokines (58). The behavior of STAT4 in human and murine cells explains this species difference: STAT4 is required in Th1 and NK cells to activate IFN- $\gamma$ transcription in response to IL-12. Type I IFNs stimulate human NK cells to activate STAT4, because the protein interacts via the STAT2 C-terminus with the type I IFN receptor complex and becomes phosphorylated on tyrosine. By contrast, the C-terminus of the murine STAT2 carries a short insertion that disrupts this interaction, preventing the recruitment and activation of STAT4 (59). Curiously, IFN- $\alpha$ is not simply inert with respect to IFN- $\gamma$ synthesis in the mouse but actually decreases the ability of murine NK cells to synthesize IFN- $\gamma$ in a STAT1-dependent manner (60). A molecular mechanism for the antagonism between STAT1, activated by type I IFN, and STAT4, activated by IL-12, remains elusive.

\section{Concluding remarks}

In recent years the role of type I IFN as antiviral agents and the prominent role of IFN- $\gamma$ as a macrophage-activating cytokine have been confirmed and extended in mice deficient in their response to one or both IFN types, but much still remains to be learned about IFN target genes that establish the antiviral state in response to different viruses, or that alter the ability of macrophages to control various pathogens. The importance of STAT-dependent (and perhaps also STAT-independent) immunoregulation of macrophage, DC, and NK cell responses by the IFNs is only beginning to be understood and will require further attention. Recent evidence for an IFNAR1-, STAT1-dependent signal occurring in the absence of ongoing immune responses to regulate MHC I expression suggests that a weak constitutive production of type I IFN keeps the host organism in a state of alertness to incoming virus (61). Despite the intensity of IFN research over several decades, the mechanisms of IFN signaling and their impact on immune responses are far from being understood.

Note. Due to space constraints, a number of important references could not be included in this article. Interested readers can find a supplementary reading list at www.jci.org/cgi/content/full/109/10/1271/DC1.

1. Pestka, S., Langer, J.A., Zoon, K.C., and Samuel, C.E. 1987. Interferons and their actions. Annu. Rev. Biochem. 56:727-777.

2. Murray, H.W. 1992. The interferons, macrophage activation, and host defense against nonviral pathogens. J. Interferon Res. 12:319-322.

3. Schindler, C., and Darnell, J.E., Jr. 1995. Transcriptional responses to polypeptide ligands: the JAK-STAT pathway. Annu. Rev. Biochem. 64:621-651.

4. Decker, T., Kovarik, P., and Meinke, A. 1997. Gas elements: a few nucleotides with a major impact on cytokine-induced gene expression. J. Interferon Cytokine Res. 17:121-134.

5. Ramana, C.V. 2000. Regulation of c-myc expression by IFN-gamma through Stat1-dependent and -independent pathways. EMBO J. 19:263-272.

6. Levy, D.E. 2002. Whence interferon? Variety in the production of interferon in response to viral infection. J. Exp. Med. 195:F15-F18.

7. Sato, M., et al. 1998. Positive feedback regulation of type I IFN genes by the IFN-inducible transcription factor IRF-7. FEBS Lett. 441:106-110

8. Marie, I., Durbin, J.E., and Levy, D.E. 1998. Differential viral induction of distinct interferon-alpha genes by positive feedback through interferon regulatory factor-7. EMBO J. 17:6660-6669.

9. Deonarain, R. 2000. Impaired antiviral response and alpha/beta interferon induction in mice lacking beta interferon. J. Virol. 74:3404-3409.

10. Durbin, J.E., Hackenmiller, R., Simon, M.C., and Levy, D.E. 1996. Targeted disruption of the mouse Stat 1 gene results in compromised innate immunity to viral disease. Cell. 84:443-450.

11. Meraz, M.A., et al. 1996. Targeted disruption of the Stat 1 gene in mice reveals unexpected physiologic specificity in the JAK-STAT signaling pathway. Cell. 84:431-442.

12. Kimura, T., et al. 1996. Essential and non-redundant roles of p48 (ISGF3 gamma) and IRF-1 in both type I and type II interferon responses, as revealed by gene targeting studies. Genes Cells. 1:115-124.

13. Park, C., Li, S., Cha, E., and Schindler, C. 2000. Immune response in Stat2 knockout mice. Immunity. 13:795-804.

14. Muller, U., et al. 1994. Functional role of type I and type II interferons in antiviral defense. Science. 264:1918-1921.

15. Tanaka, N., et al. 1998. Type I interferons are essential mediators of apoptotic death in virally infected cells. Genes Cells. 3:29-37.

16. Pavlovic, J., and Staeheli, P. 1991. The antiviral potentials of Mx proteins. J. Interferon Res. 11:215-219.

17. Garcia-Sastre, A., et al. 1998. The role of interferon in influenza virus tissue tropism. J. Virol. 72:8550-8558.

18. Durbin, J.E., et al. 2000. Type I IFN modulates innate and specific antiviral immunity. J. Immunol. 164:4220-4228.

19. Dalton, D.K., et al. 1993. Multiple defects of immune cell function in mice with disrupted interferon-gamma genes. Science. 259:1739-1742.

20. Huang, S., et al. 1993. Immune response in mice that lack the interferon-gamma receptor. Science. 259:1742-1745.

21.van den Broek, M.F., Muller, U., Huang, S., Zinkernagel, R.M., and Aguet, M. 1995. Immune defence in mice lacking type I and/or type II interferon receptors. Immunol. Rev. 148:5-18.

22. Bogdan, C. 2000. The function of type I interferons in antimicrobial immunity. Curr. Opin. Immunol. 12:419-424.

23. Navarro, L., and David, M. 1999. p38-dependent activation of interferon regulatory factor 3 by lipopolysaccharide. J. Biol. Chem. 274:35535-35538.

24. Kawai, T., et al. 2001. Lipopolysaccharide stimulates the MyD88-independent pathway and results in activation of IFN-regulatory factor 3 and the expression of a subset of lipopolysaccharide-inducible genes. J. Immunol. 167:5887-5894.

25. Manca, C., et al. 2001. Virulence of a Mycobacterium tuberculosis clinical isolate in mice is determined by failure to induce Th 1 type immunity and is associated with induction of IFN-alpha/beta. Proc. Natl. Acad. Sci. USA. 98:5752-5757.

26. Cooper, A.M., Pearl, J.E., Brooks, J.V., Ehlers, S., and Orme, I.M. 2000. Expression of the nitric oxide synthase 2 gene is not essential for early control of Mycobacterium tuberculosis in the murine lung. Infect. Immun. 68:6879-6882.

27. Diefenbach, A., et al. 1998. Type 1 interferon (IFNalpha/beta) and type 2 nitric oxide synthase regulate the innate immune response to a protozoan parasite. Immunity. 8:77-87.

28. Toshchakov, V., et al. 2002. TLR4, but not TLR2, mediates IFN-beta- 
induced STAT1alpha/beta-dependent gene expression in macrophages. Nat. Immunol. 3:392-398.

29. Karaghiosoff, M., et al. 2000. Partial impairment of cytokine responses in Tyk2-deficient mice. Immunity. 13:549-560.

30. Kiderlen, A.F., Kaufmann, S.H., and Lohmann-Matthes, M.L. 1984 Protection of mice against the intracellular bacterium Listeria monocytogenes by recombinant immune interferon. Eur. J. Immunol. 14:964-967.

31. Nauciel, C., and Espinasse-Maes, F. 1992. Role of gamma interferon and tumor necrosis factor alpha in resistance to Salmonella typhimurium infection. Infect. Immun. 60:450-454.

32. Cooper, A.M., et al. 1993. Disseminated tuberculosis in interferon gamma gene-disrupted mice. J. Exp. Med. 178:2243-2247.

33. Rottenberg, M.E., et al. 2000. Regulation and role of IFN-gamma in the innate resistance to infection with Chlamydia pneumoniae. J. Immunol. 164:4812-4818.

34. Doherty, T.M., and Sher, A. 1997. Defects in cell-mediated immunity affect chronic, but not innate, resistance of mice to Mycobacterium avium infection. J. Immunol. 158:4822-4831.

35. VanCott, J.L., et al. 1998. Regulation of host immune responses by modification of Salmonella virulence genes. Nat. Med. 4:1247-1252.

36. Harty, J.T., and Bevan, M.J. 1995. Specific immunity to Listeria monocytogenes in the absence of IFN gamma. Immunity. 3:109-117.

37. Bancroft, G.J., Schreiber, R.D., and Unanue, E.R. 1991. Natural immunity: a T-cell-independent pathway of macrophage activation, defined in the scid mouse. Immunol. Rev. 124:5-24.

38. Dupuis, S., et al. 2000. Human interferon-gamma-mediated immunity is a genetically controlled continuous trait that determines the outcome of mycobacterial invasion. Immunol. Rev. 178:129-137.

39. Dupuis, S., et al. 2001. Impairment of mycobacterial but not viral immunity by a germline human STAT1 mutation. Science. 293:300-303.

40. Decker, T., and Kovarik, P. 2000. Serine phosphorylation of STATs. Oncogene. 19:2628-2637.

41. Stoiber, D., Stockinger, S., Steinlein, P., Kovarik, J., and Decker, T. 2001. Listeria monocytogenes modulates macrophage cytokine responses through STAT serine phosphorylation and the induction of suppressor of cytokine signaling 3. J. Immunol. 166:466-472.

42. Stoiber, D., et al. 1999. Lipopolysaccharide induces in macrophages the synthesis of the suppressor of cytokine signaling 3 and suppresses signal transduction in response to the activating factor IFN-gamma. J. Immunol. 163:2640-2647.

43. Lanzavecchia, A., and Sallusto, F. 2001. Regulation of T cell immunity by dendritic cells. Cell. 106:263-266.

44. Lanzavecchia, A., and Sallusto, F. 2001. The instructive role of dendritic cells on T cell responses: lineages, plasticity and kinetics. Curr. Opin. Immunol. 13:291-298.
45. Liu, Y.J., Kanzler, H., Soumelis, V., and Gilliet, M. 2001. Dendritic cell lineage, plasticity and cross-regulation. Nat. Immunol. 2:585-589.

46. Cella, M., et al. 1999. Plasmacytoid monocytes migrate to inflamed lymph nodes and produce large amounts of type I interferon. Nat. Med. 5:919-923.

47. Siegal, F.P., et al. 1999. The nature of the principal type 1 interferonproducing cells in human blood. Science. 284:1835-1837.

48. Cella, M., et al. 1999. Maturation, activation, and protection of dendritic cells induced by double-stranded RNA. J. Exp. Med. 189:821-829.

49. Kadowaki, N., Antonenko, S., and Liu, Y.J. 2001. Distinct CpG DNA and polyinosinic-polycytidylic acid double-stranded RNA, respectively, stimulate CD11c- type 2 dendritic cell precursors and CD11c+ dendritic cells to produce type I IFN. J. Immunol. 166:2291-2295.

50. Kadowaki, N., et al. 2001. Subsets of human dendritic cell precursors express different toll-like receptors and respond to different microbial antigens. J. Exp. Med. 194:863-869.

51. Kadowaki, N., Antonenko, S., Lau, J.Y., and Liu, Y.J. 2000. Natural interferon alpha/beta-producing cells link innate and adaptive immunity. J. Exp. Med. 192:219-226.

52. McRae, B.L., Nagai, T., Semnani, R.T., van Seventer, J.M., and van Seventer, G.A. 2000. Interferon-alpha and -beta inhibit the in vitro differentiation of immunocompetent human dendritic cells from CD14(+) precursors. Blood. 96:210-217.

53. Lehner, M., Felzmann, T., Clodi, K., and Holter, W. 2001. Type I interferons in combination with bacterial stimuli induce apoptosis of monocyte-derived dendritic cells. Blood. 98:736-742.

54. Nakano, H., Yanagita, M., and Gunn, M.D. 2001. Cd11c(+)b220(+)gr$1(+)$ cells in mouse lymph nodes and spleen display characteristics of plasmacytoid dendritic cells. J. Exp. Med. 194:1171-1178.

55. Asselin-Paturel, C., et al. 2001. Mouse type I IFN-producing cells are immature APCs with plasmacytoid morphology. Nat. Immunol. 2:1144-1150

56. McRae, B.L., Semnani, R.T., Hayes, M.P., and van Seventer, G.A. 1998. Type I IFNs inhibit human dendritic cell IL-12 production and Th1 cell development. J. Immunol. 160:4298-4304.

57. Le Bon, A., et al. 2001. Type i interferons potently enhance humoral immunity and can promote isotype switching by stimulating dendritic cells in vivo. Immunity. 14:461-470.

58. Sinigaglia, F., D’Ambrosio, D., and Rogge, L. 1999. Type I interferons and the Th1/Th2 paradigm. Dev. Comp. Immunol. 23:657-663.

59. Farrar, D.J., et al. 2000. Selective loss of type I interferon-induced STAT4 activation caused by a minisatellite insertion in mouse Stat2. Nat. Immunol. 1:65-69.

60 . Nguyen, K.B., et al. 2000. Interferon $\alpha / \beta$-mediated inhibition and promotion of interferon $\gamma$ : STAT1 resolves a paradox. Nat. Immunol. 1:70-76.

61. Taniguchi, T., and Takaoka, A. 2001. A weak signal for strong responses: interferon-alpha/beta revisited. Nat. Rev. Mol. Cell Biol. 2:378-386. 